\title{
A GIS-Based Integrated Model for Exploring Effects of Land Use Changes on Transport Demand: The Case of Dar es Salaam, Tanzania
}

\author{
Wilfred Gordian Kazaura \\ Department of Urban and Regional Planning, School of Spatial Planning and Social Science, Ardhi University, Dar es Salaam, Tanzania \\ Email: wkazaura@yahoo.com
}

How to cite this paper: Kazaura, W. G. (2019). A GIS-Based Integrated Model for Exploring Effects of Land Use Changes on Transport Demand: The Case of Dar es Salaam, Tanzania Current Urban Studies, 7, 459-479.

https://doi.org/10.4236/cus.2019.73023

Received: July 6, 2019

Accepted: September 22, 2019

Published: September 25, 2019

Copyright ( 2019 by author(s) and Scientific Research Publishing Inc. This work is licensed under the Creative Commons Attribution International License (CC BY 4.0).

http://creativecommons.org/licenses/by/4.0/

\begin{abstract}
Land use patterns essentially determine activity centre locations and opportunities for trip generation and attraction. Land uses signify the magnitude of travel demand and availability of transport patterns influences the future land uses. A number of literatures on land use and transport interactions show that the effects of land use change on transport appear to be more direct and stronger than the reverse. The main cause, in large part, is the important roles of trip generation and attraction, whose change of spatial distribution basically increases the number of trips and distances travelled between activity centres. Ignoring the mutual influences for the change between land use and transportation in long-term forecasting and planning can lead to decisions with unintended and undesirable consequences. This is more critical in developing countries cities where long-term travel demand forecasting and transportation infrastructure planning is seldom done as well as changes in land use are considerably high compared with the supply of transport infrastructure. This paper therefore reports upon a GIS-based integrated land use and transport model developed to determine effects of land use changes on travel demand. The model is developed based on vector map layers of the planned land uses, and changes obtained by overlaying the subsequent layers in ten-year intervals obtained from satellite images. The model is capable of performing a spatial-temporal analysis of land uses and illustrating effects on travel demand. The modelling system also supports analysis of policy measures that alternatively reduce the number of vehicle trips generated in the planned area.
\end{abstract}

\section{Keywords}

Land Use Change, Transport Demand, Integrated Land Use and Transport, GIS-Based Model 


\section{Introduction}

The development of a GIS-based model is among the fundamental strategies for addressing the effect of land use change in transport networks. Essentially, land use change emerges over time, and largely increases the magnitude of travel demands that affect the forecasted transport infrastructure; however, provision of transport infrastructure is significantly low. A GIS-based model is an important tool for detecting, analysing and integrating the associated land use and transport changes and their interlationships. Effective application of GIS-based model in developing countries is mainly challenged by inputs for the system manipulations that include data, hardware and manpower; the spatial-temporal integration capabilities; and the formulation of future alternatives prospects. The development of this system intends to achieve three objectives: 1 ) to efficiently determine the rates of spatial change for different land use categories in defined time intervals from map layers; 2 ) to effectively integrate the spatial features with the respective attributes and determine the number of trips generated by changed land uses within the given time intervals; 3 ) to efficiently analyse and present different scenarios for addressing the effects of land use change in the planned settlements.

The system developed to facilitate four major functions: first was determination of rates of land use change whereby the layer for the planned land uses was used as baseline layer and succeeding land uses were used as targeted layers. The changes were obtained by overlaying the targeted layers to baseline layers. The rates of change were presented in percentages of total change of the specific land use category. Secondly, was to determine variations of non-spatial or attributes of the changed spatial features. The variables for attribute variations include: land parcel, area (ground and floor area) and coefficients of vehicle trip generated in the planned settlement. Coefficients were measured as trip rate per area in square meters; for non residential land uses, and trip rate per household or dwelling unit in residential land uses. Thirdly, was to determine the number of vehicle trips before and after land use change and compute the difference between trips generated before and after land use change. The differences are also obtained for the number of vehicle trips forecasted by using trip rates provided in the manual and trips forecasted by the application of new trip rates obtained in the study area. The differences between a number of trips generated before and after land use change are reasonably high, but differences between trips generated by using manual rates and those generated using new rates are extremely high. The last part includes the data view for editing and modifying data, and the analysis view for presentation of different results and scenarios. The system also allows application of different options in attempting different alternatives for interventions and plans future developments.

Baseline layer was obtained from the original land use map planned in 1992 for the entire study area, while targeted layers include land uses obtained from 
high resolution satellite images of the years of 2002 and 2012. The original plans were scanned, geo-referenced and digitized in Arc-GIS software. The changes were determined by simply overlaying the land uses obtained from satellite images to land uses of the baseline layer. Spatial differences were verified physically in the study area by using physical measurements tools such as hand-held GPS and tape measures. On the other hand, the land parcel attribute data were direct entered in the system or linked from other databases by using unique identifier values. Integration between the two databases were performed by using stand alone computers, however, the system supports Object-Oriented Database Connectivity (ODBC) tool for server based systems.

The model has different powerful functions of storing, querying, analysing and displaying spatial and attributes data in an integrated environment. Given that time is an inseparable component of all changes taking place in the real world, nevertheless, there have been many research efforts on temporal GIS. By involving temporal data, the system is capable of performing spatial-temporal analysis for land use and transportation interactions, which is the great challenge in transport planning as reported in the literature. Basically, the system can detect the changed land parcel or plot and determine the added or substracted area for each land use category such as residential, commercial, institutions, industrial and open spaces. Furthermore, the change of travel demand is also determined by computing vehicle trips generated by the changed land parcels that depict the additional vehicle trips on each land use category. The model outputs are presented in graphs, charts and tables, and comparisons are presented in percentages.

\section{Literature Review}

Land use and transportation are inseparable components of all changes that take place in the real world. A transportation system, for example, evolves over time through its construction, improvement and maintenance projects. Many studies on land use and transportation interactions conducted in the past few decades (Shaw \& Xin, 2003; Murai, 1998; Wagner, 1998) described the conventional and static approach of addressing land use change in transport planning. Land use changes and transportation systems were treated as independent to each other. Therefore, the mutual relationships between land uses changes on the travel demand were not systematically determined. It led to a deprived supply of transportation systems and disadvantaged system improvements that resulted into chaotic urban transport challenges.

In recent years, there has been renewed interest in land use-transportation interaction models. These are systems that offer powerful functions of handling spatial (where) and thematic (what) data in an integrated environment, and can be extended to include the temporal (when) data for studies of land use and transportation interactions (Kwan, 2000; Aronoff, 2002; Kenneth \& Lynch, 1995). GIS-based transportation provides a dynamic and interactive environ- 
ment that is much more flexible during travel demand forecasting. Transport planner can not only manipulate the individual and household travel patterns and land use change attributes of a scene and its features, but also, can change the data views, alter parameters, query data and present results easily (Kwan \& Lee, 2003). Each GIS map layer is treated as a snapshot that captures the spatial pattern of a selected theme at a given time. Users often need to contact the original source or read a metadata document to find out the temporal component of a GIS data set. This approach of storing geographic data in snapshot GIS layers without explicit treatment of time introduces many shortcomings when we need to examine changes of spatial and attribute data over time (Yuan, 1999).

The problem becomes even more complex when we need to take into account the time lag effect between land use and transportation changes (Worboys, 1998). Certain land use changes (for example opening of a major shopping centre) may have an immediate major impact on traffic volumes in their surrounding areas, while other land use changes (for instance upgrading or redevelopment project) tend to induce changes in traffic over a longer time period. Similarly, different transportation projects (for example construction of a bus terminal, expansion of existing roads, or building of other transport systems) are likely to have impact on land use patters over different time horizons. In these cases, a transport planner must analyse the changes introduced by each phenomenon at a set/particular period of time.

The new approaches noticeably provide adequate supports for the spatial-temporal query and analysis; however, the growing research efforts insist the adoption of the key concept of temporal GIS. Kwan (2000), Shaw (2006) and Langran (1992) suggest that a temporal GIS must include a history of spatial changes in the real world. Its data model should have a space-time composite that attempts to combine the separate GIS layers captured in different times and present them as a single GIS layer that covers all changes that have occurred over all time periods. In a space-time (ST) composite approach, a GIS layer represents the smallest geographic unit that has experienced changes in history and keeps track of changes over time.

In assessing the need of urban planning tools for determining the rates of informal and formal land use change, Michael (2006) and Miller and Wu (2010) insisted upon the application of spatial analysis tools such as Geographical Information System and Remote Sensing technology. The performances of models developed by application of GIS named GIS transportation (GIS-T) were slightly weak compared with recent GIS-based integrated land use and transport cellular models. Basically, these are models developed by the application of GIS and remote sensing data in order to determine the rates of land use change in temporal scales. The model applies remote sensing data whereby raster pixels facilitates the formation of grid cells mainly Cellular Automata (CA). Changes in land use and building and their impact on travel costs, time, frequency and distance are sequentially analysed in each cell and stored in GIS databases (Iacono et al., 
2008).

As indicated by Waddell et al. (2003) and Sun et al. (2000), previous GIS-based models were weak in spatial analysis and have limited functions in integrating and aggregating travel attributes because they were developed in a space-oriented approach (SOA). But Yang (2007) proposed GIS-based integrated land use and transport model that should be Object Oriented approach (OOA) and effective in integration of individual or household travel data, land use characteristics and travel attributes in space and time composites for better analysis of spatial and attribute changes within a defined period of time. He suggested GIS packages such as Arc-GIS and Trans-CAD which are capable of determining land uses change by the application of geo referenced vector maps and raster images. Finally, Wei and Zhou (2006) suggested the following to be encountered in GIS-T development:

1) The system should include temporal GIS databases that allow investigations of land use and transportation interaction at different temporal scales which include determination of short and long-term effects of land use change in transport networks.

2) The system must permit analysts to investigate relationships among all GIS map layers and raster images that represent various forces of land use change such as population, economic development and new investments underlying the process of land use and transportation interaction at different spatial scales for various time periods.

3) The system should provide methods for a systematic exploration of relevant data sets and offer visualization tools and basic summary statistics to show the land use and transportation interaction at different land use change patterns.

\section{The Study Area}

The study was conducted in Dar es Salaam, the largest city in Tanzania located in the eastern part along the shores of the Indian Ocean. As indicated in Map 1, the City is located between $5^{\circ} 30^{\prime}$ to $7^{\circ} 15^{\prime}$ South and $38^{\circ}$ to $39^{\circ}$ East. The City is boarded by Coastal region which comprises Bagamoyo, Kibaha, Kisarawe and Mkuranga Districts.

\section{Data Collection}

Two categories of data were collected in the study area. The first category includes land use change data obtained by using the planed land uses of the year 1992 and satellite images of the years 2002 and 2012. The planned land uses were obtained from the Ministry of Lands Housing and Human Settlement Development in hard copies. The hard copies were digitizing by using Arc-GIS software and land use layer presented in GIS system. Subsequently, the 2002 and 2012 land uses were obtained by digitizing the land uses displayed by the satellite images of year 2002 and year 2014. The differences between planned land uses and land uses of year 2002 and year 2012 were obtained by application of spatial 


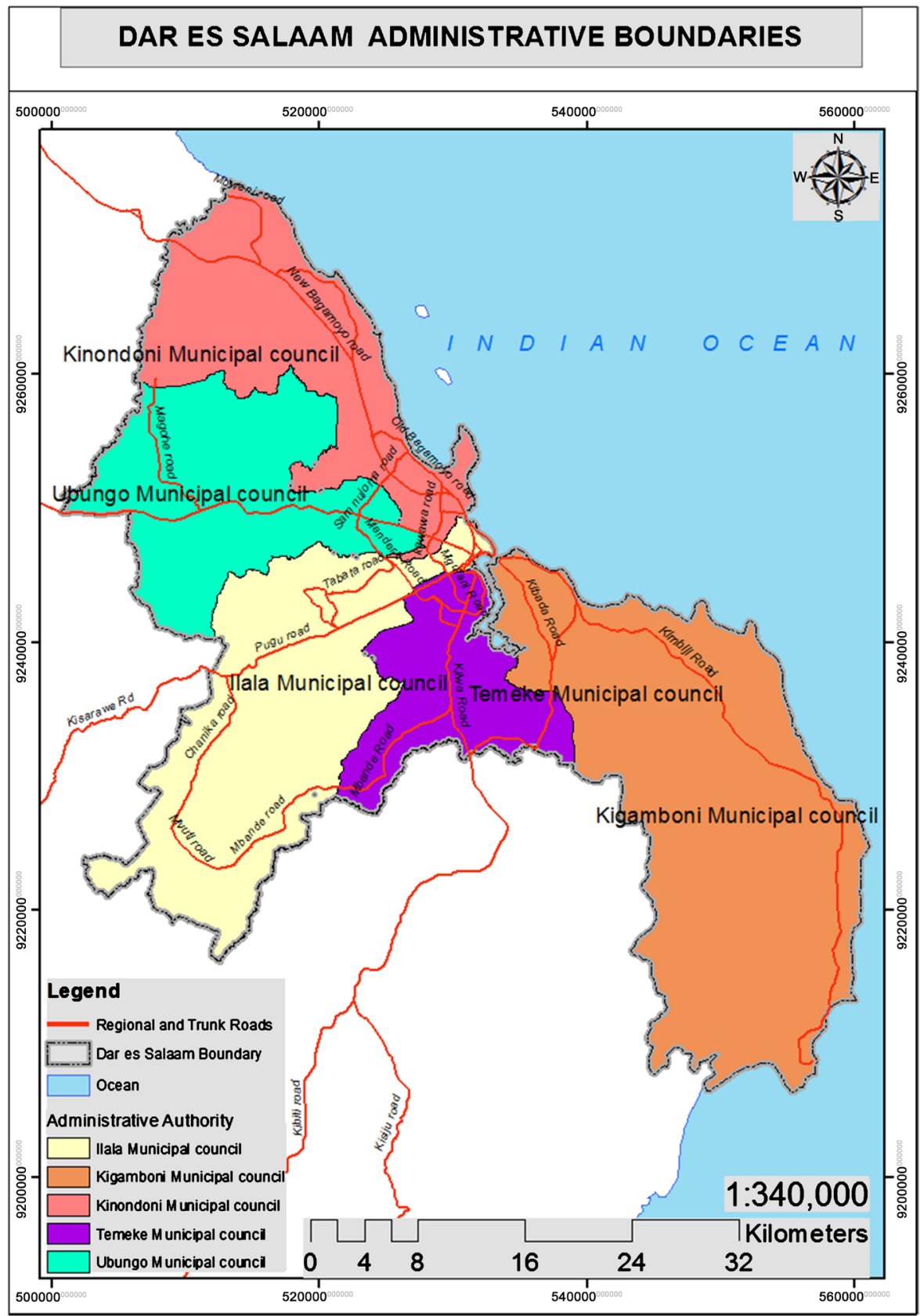

Source: Survey and Mapping Division, Tanzania.

Map 1. Dar es Salaam city showing administrative boundaries.

analysis tools through overlay functions. The observed spatial differences between planned land uses in year 1992, land uses of year 2001 and land uses of year 2012 have indicated the great effects of land use change on transport demand.

The second category includes socio-economic and travel attributes data collected by performing household survey in the study area. To determine the sample size, a random sampling method was applied to avoid biases of respondents in the study area. The respondent population were total number of houses or dwelling units, which were 6743 houses. 
The sample size was obtained by the formula $n=N /\left(1+N(e)^{2}\right)$ where $n$ is the sample size, $N$ is total number of houses which is the population, and $e$ is the level of precision, that is 0.05 at $95 \%$ confidence level.

Therefore:

$$
\begin{aligned}
& n=6743 /\left(1+6743 \times(0.05)^{2}\right) \\
& n=6743 / 17.87 \\
& n=377.33 \\
& n=377
\end{aligned}
$$

The sample size is 377 houses or dwellings units. The limitations during the household survey include inaccessibility to the sampled houses, unavailability and unwillingness of interviewees, however, eighty one percent (81\%) that is 304 households of the sample size were interviewed. The respondent was required to state the chain of trips made for the previous working day, and for each trip, the provided data included start and end times, origin and destination of locations, purpose, mode of transport used and distance travelled. Also, the household characteristics data were collected.

Other secondary data such as planning standards and parameters were collected from Urban Planning Guidelines of 2007 and Urban Land Use and Transport Manuals of 2008.

\section{Design of Integrated GIS-Based System}

Like many other spatial analysis systems, an integrated GIS-based land use and transport system involve three major elements. First is the time element that defines when the changes have happened. For this item, ten year intervals were applied to determine the rate of changes, whereby the planned spatial and non-spatial data in 1992 were applied as baseline information, whereas the data in 2002 and 2012 were applied to determine the rate of change for and uses and transport in the study area. Second is the location element that determines where the changes take place. It involves the determination of sizes, area and other spatial differences between planned, ten years and twenty years after implementation of the land use plan. This time horizon was restricted by the availability of satellite images in suppliers archives, and it has limited the consistency of model development. Thirdly is the attribute element that describes to what extent the changes have happened and how they are interrelated with each other. It includes determination of types, use, quantities and compositions of spatial attributes within the defined time intervals.

\subsection{The Approach of System Development}

Most GIS packages today already provide powerful functions of handling spatial and attribute data in an integrated environment. This study therefore takes an approach of developing GIS-based package that incorporates temporal data in 
exploring the interactions between land use and transportation. Functions of the system are mainly focusing on developing temporal GIS databases by adding time-based analysis function, and integrating temporal data with spatial and attribute data in order to support spatial-temporal analysis.

\subsubsection{System Data Requirements}

Data collected for the system contain time, location, and attribute elements that explore land use and transportation interaction. In this framework, all data related to the land uses and the transport also have to define the time frame in temporal bases. Since there are spatial or attribute changes which take place over the given time, time is therefore used as the key component to facilitate spatial-temporal analysis.

Spatial data are defined as land use layers that include land parcels of the planned and allocated plots and roads network, while, attribute data include all data that describe either the land parcel or the road link. The land parcel is identified by the unique number to facilitate integrations with attribute data. Attributes normally define the sizes or area of the land parcel which is either ground area only for single storey buildings and floor area for multi-storey buildings, the use of land parcel which is either residential, commercial, institution, industrial and open spaces, the location which is defined by sub ward and ward names, and standard coefficient of vehicle trips to be generated by respective land parcel. Attributes for road link include link identifier which also is unique value together with road class which is either arterial collector, feeder and access street; road condition which is either tarmac, gravel or earth road, and traffic volume for the Average Daily Traffic (ADT) data. Time based data are presented in years, and it depicts the year that land uses and road network layers had been captured.

\subsubsection{System Development}

The system was developed by using visual basic and C++ programming languages together with Map Object, Arc Object and My SQL. Visual basic and $\mathrm{C}++$ were used to develop the graphical user interfaces and commands for the best application of this system. Map Object and Arc Objec were applied to develop functional tools which are effective for GIS applications, while My SQL help to develop relationships for databases for integration.

As indicated in Figure 1 below, a unified modelling structure of the temporal GIS database design was applied to develop an interactive GIS-based system. Within the system, the feature objects from land uses and road layers together with their interelated attributes are converted into geo databases. The geo databases are set into years to facilitate temporal exploratory functions by creating space-time (ST) and object oriented composite geo-databases. This becomes more efficient when dealing with large temporal GIS databases. Finally the Visual Basic programs were used to generate an interface which automatically creates a time object class that can read and record all unique changes over time. 


\subsubsection{System Set Up and Functions}

As presented in Figure 2 below, the model contains three major windows that are: Main menu, administrative and GIS operation window.

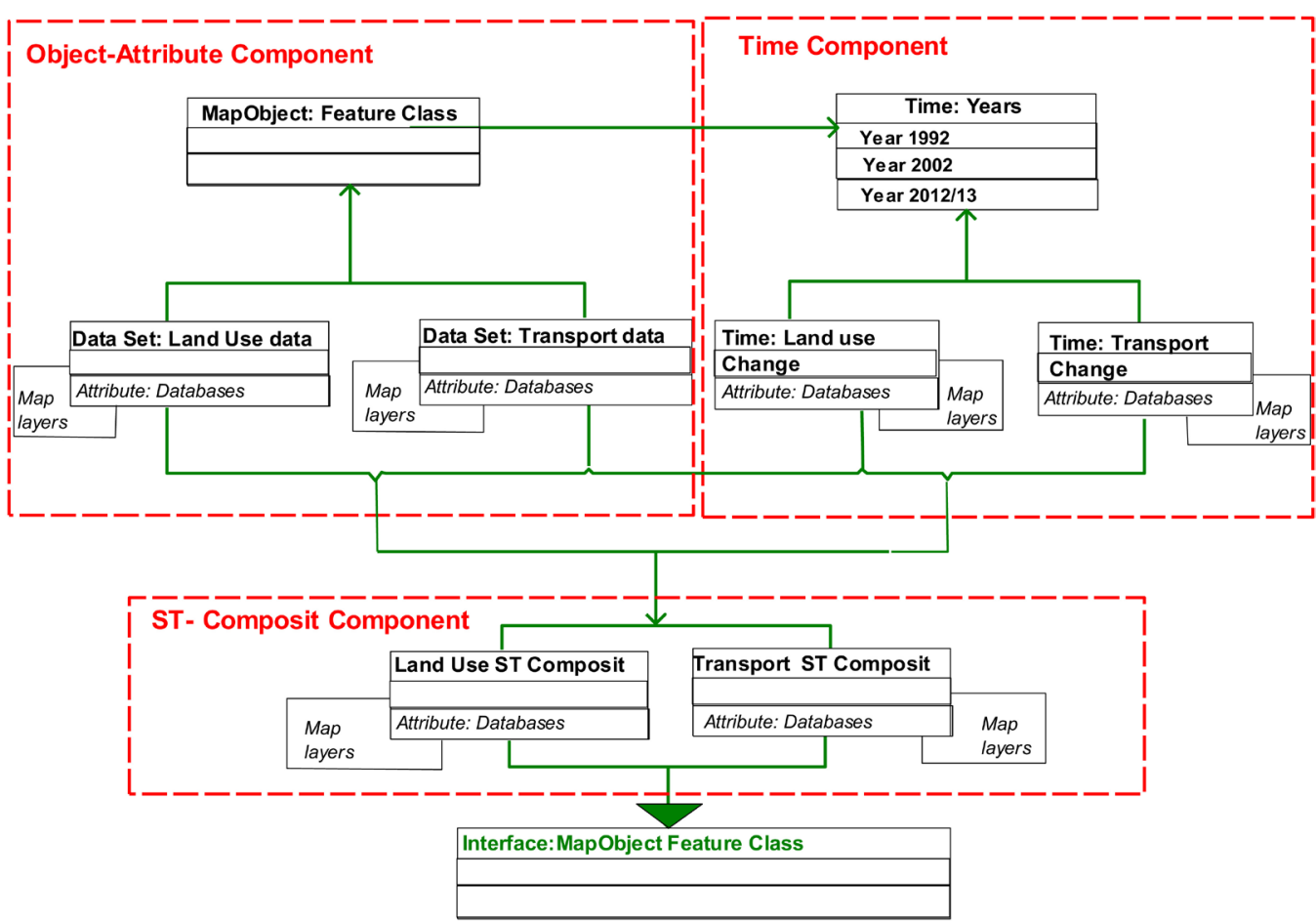

Figure 1. The temporal GIS-based system design.
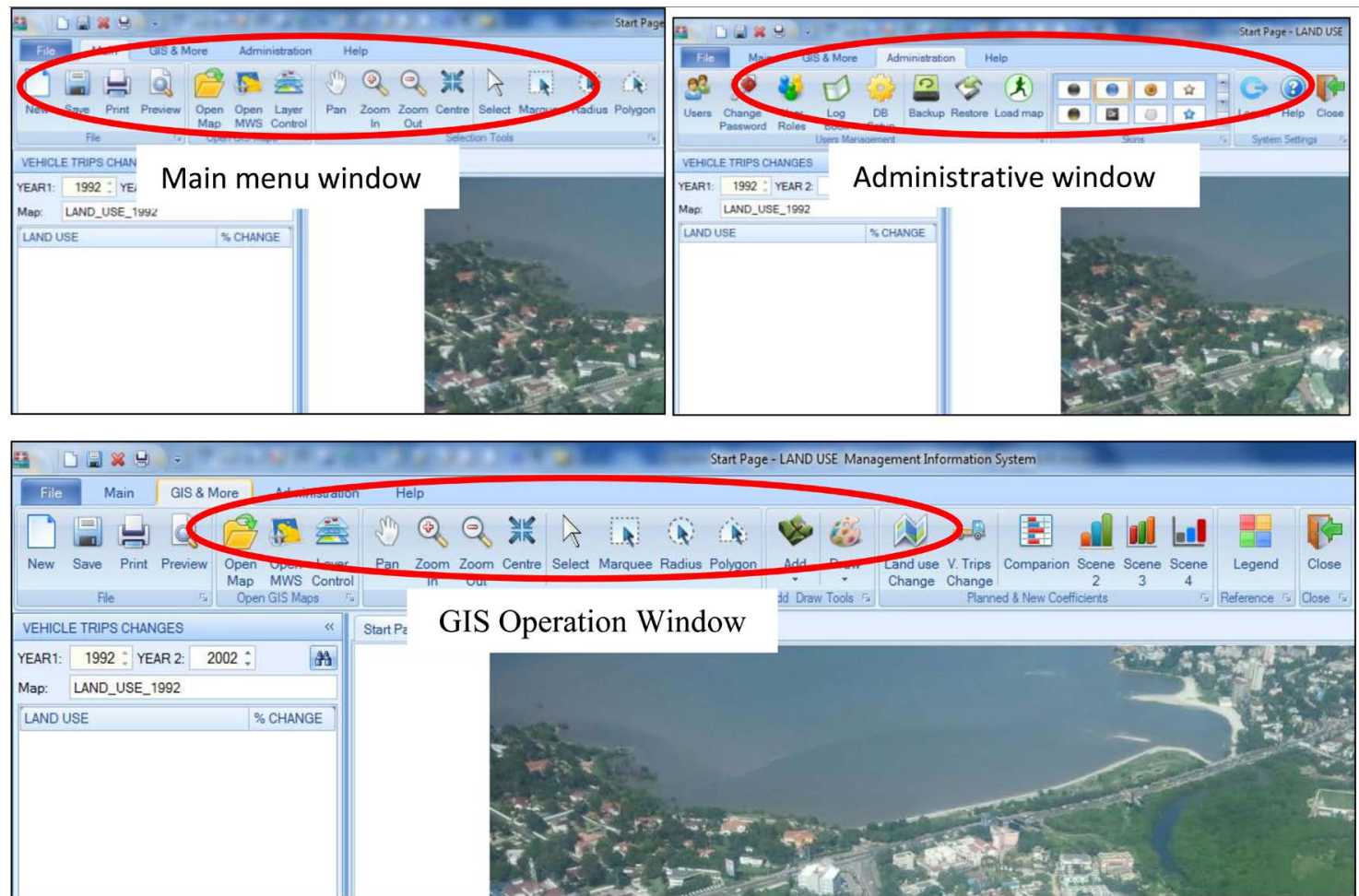

Figure 2. System windows set up and functions. 
Main window is for opening, copying and closing the system, operation window is for loading map layers from GIS systems and attribute tables from different databases and integrating map layers with attributes tables that create geo-databases, while administrative window is for users' registration, addition of tools, security configuration back-up created and data storage.

\subsubsection{Integrations}

The system is provided with Open Database Connectivity (ODBC) that is compiled in dynamic link libraries (DLLs) for effective GIS integration functions. In this model, three DLLs are added to link spatial and attribute data of the years 1992, 2002 and 2012. Figure 3 below shows the dialog window for loading map layers and attribute data in order to create an integrated GIS database. The unique identifiers (IDs) in map layers and attribute tables are automatically connected with ODBC operations or join command. The integrated files unify attributes and object data and facilitate spatial analysis. The system is dynamic and flexible for loading map layers and attributes of different formats. Spatial data in tabs, shape-files, bmp, gif, tiff, jpeg, map formats and attribute data in Microsoft Access, Excel, Dbase, and Lotus are compatible to the system.

\subsection{Analysis and Presentation}

The system analysis is performed to depict three major items; first is the extent to which land uses had changed, second is the excessive vehicle trips generated

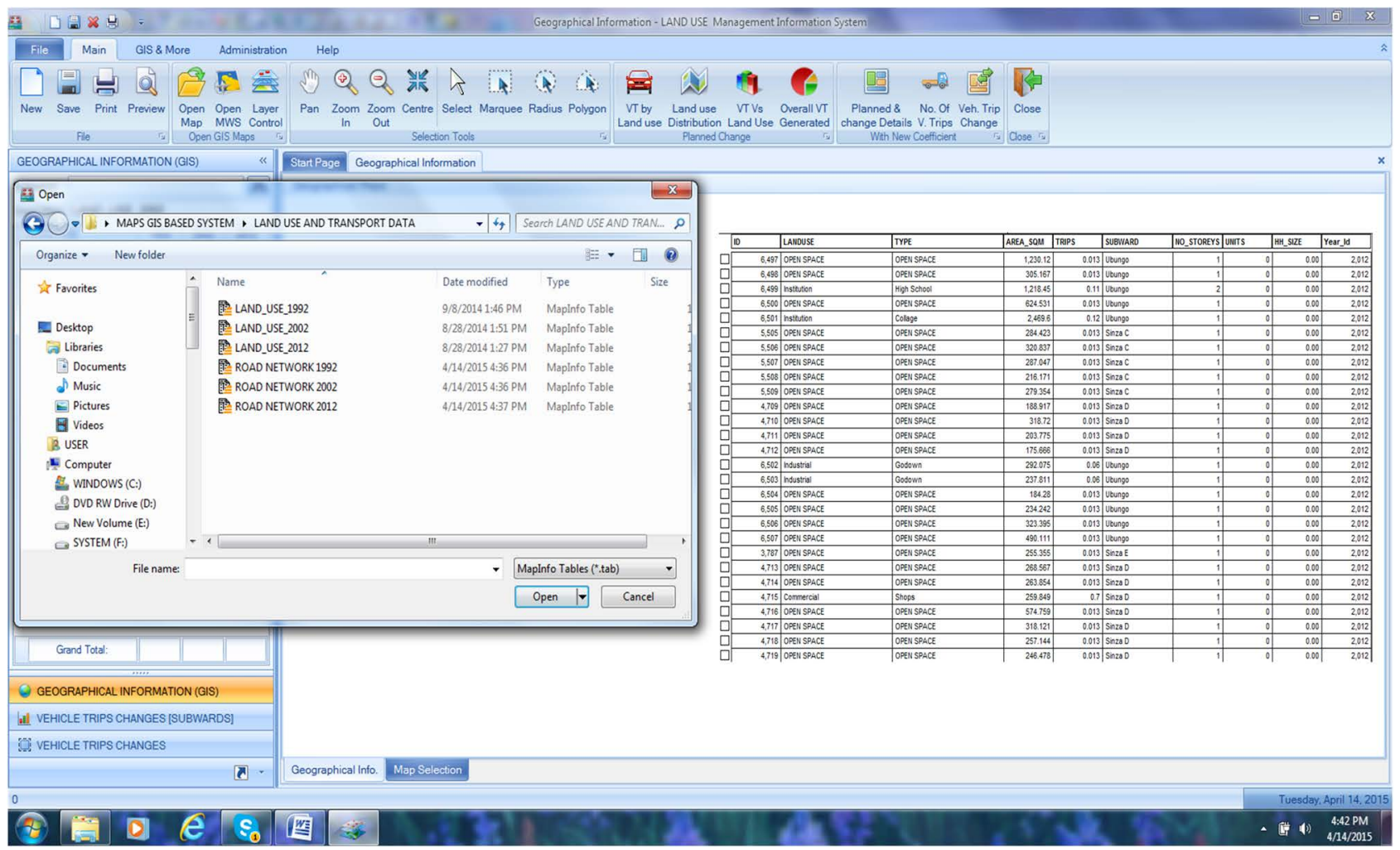

Figure 3. System loading map layers and attribute data. 
in the study area caused by land use change, and lastly is the scenario for different alternatives in order to minimize effects of land use change in travel demand.

\subsubsection{Land Use Change Presentations}

This is the part of the system that determines the changed land parcels by the application of overlay functions whereby planned map layers of the year 1992 are used as a baseline layer while the subsequent layers for the years 2002 and 2012 are targeted layers. The targeted layers are overlaid to the baseline layer to determine spatial difference. As presented in Figure 4 below, the system detects the land parcels which have changed their uses and presents them in different colours. The highlighted green coloured polygons are the plots which have changed their uses between years 1992 and 2012.

On the other hand, distributions of residential, commercial, open spaces, institutions and industrial land uses are presented in tables, graphs and charts. Basing on the planned land uses of 1992, the area for 2002 and 2012 land uses are computed and spatial differences presented in percentages. As presented in Figure 5 below, areas for commercial, institution and industrial land uses are considerably increased in 2002 and 2012, while at the same times, areas for open spaces are slightly decreased. On the other hand, areas for residential land use increased in 2002 but decreased in 2012, indicating that in 2002 open spaces and other land uses were changed to residential development, but in 2012 some of residential buildings were converted to commercial, institutions and industrial developments.

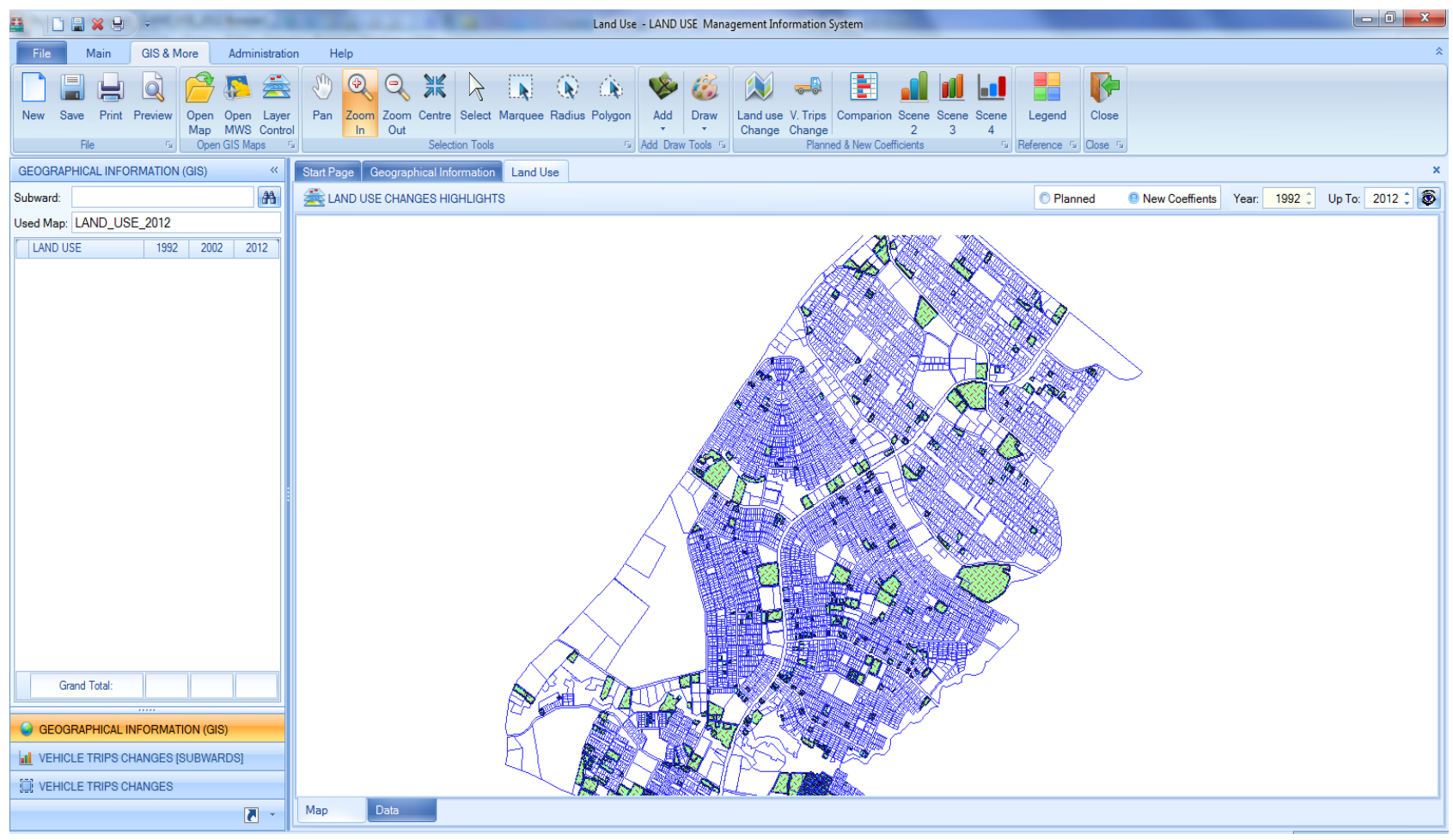

Figure 4. Land parcels changed to different uses between years 1992-2012. 


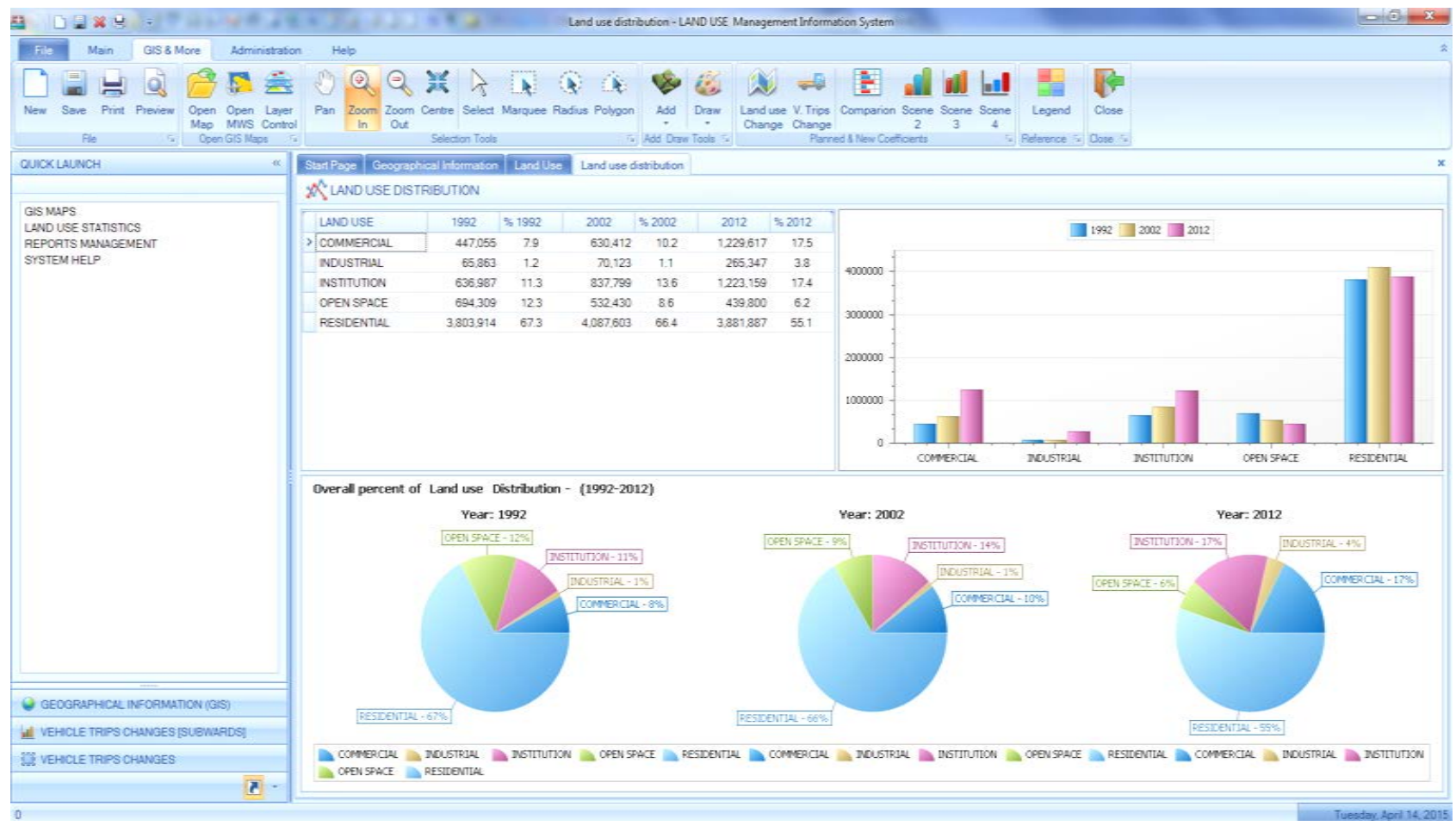

Figure 5. Land use distributions in year 1992, 2002 and 2012.

\subsubsection{Vehicle Trips Generated by Changed Land Uses}

This is the model component that determines number of vehicle trips generated by the land parcels. Overlay operations are also applied to detect the changed plots. Vehicle trips generated by individual plot are computed by multiplying the area of the plot with the standard coefficient of trip generation rates for each kind of land use. As presented in Figure 6 below, the system displays outputs of additional vehicle trips in map window that are categorized into normal, moderate, high and extremely high. Normal indicate the plots which have been changed and generate less than 50 vehicle trips, moderate is for plots that generate between 50 and 75 trips, high shows plots that generate between 75 and 100 trips while extremely high are for plots that generate more than 100 vehicle trips.

The system also determined the aggregated number of vehicle trips generated in residential, commercial, open spaces, institutions and industrial land uses for the years 1992, 2002 and 2012. As presented in Figure 7 below, vehicle trips generated by residential and commercial land uses rapidly increased; trips for institutions and industries slightly increased, while trips for open space are decreasing.

The rise of vehicle trips generated in residential and commercial land uses is mainly caused by the increased population and multiplication of the number of households accommodated in houses, together with overgrowing of commercial activities such as whole sale and retail shops, bar, restaurants, hotels, local markets and shopping malls that attract more traffic during peak and non-peak hours. 


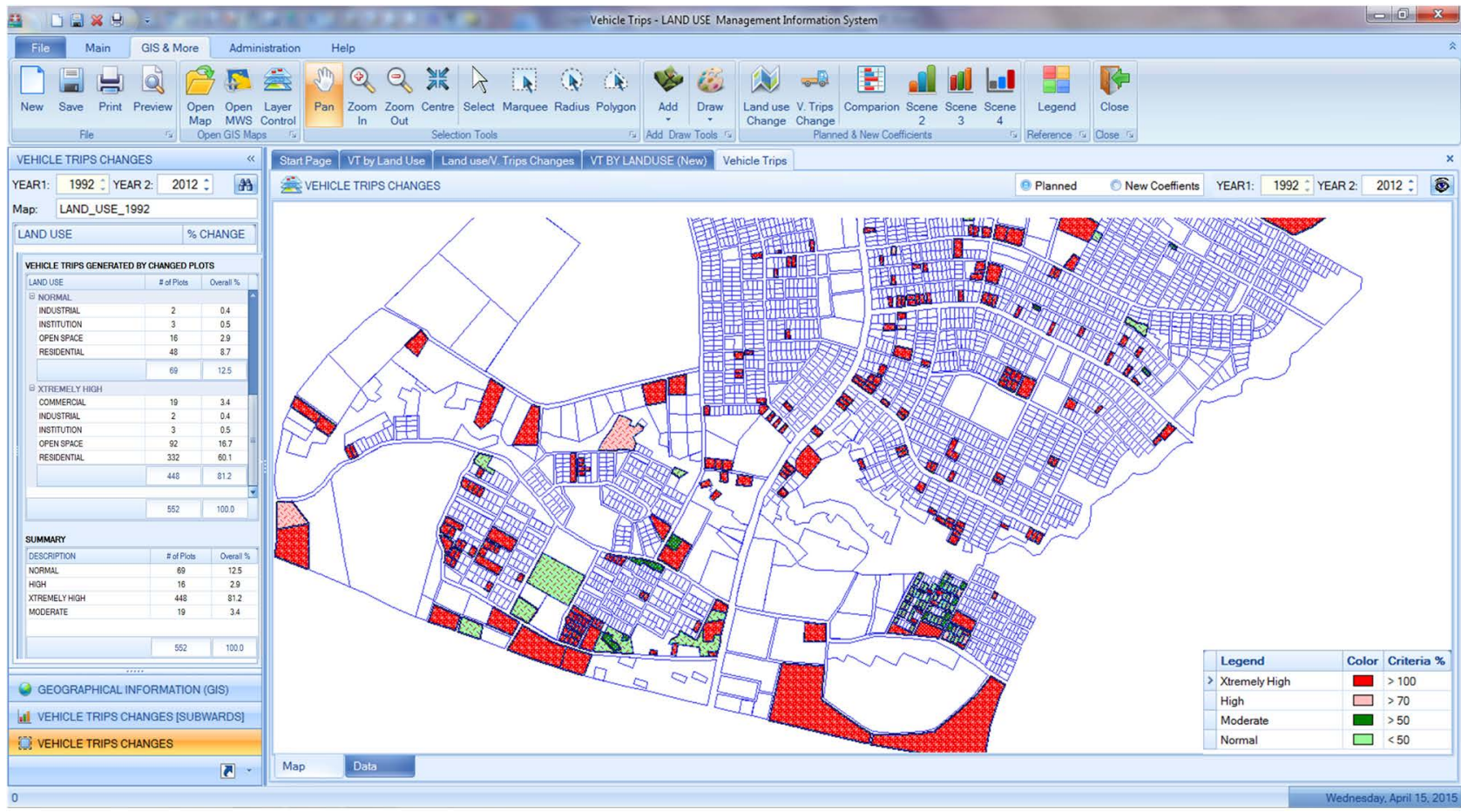

Figure 6. Categories of vehicle trips generated by changed land parcels.

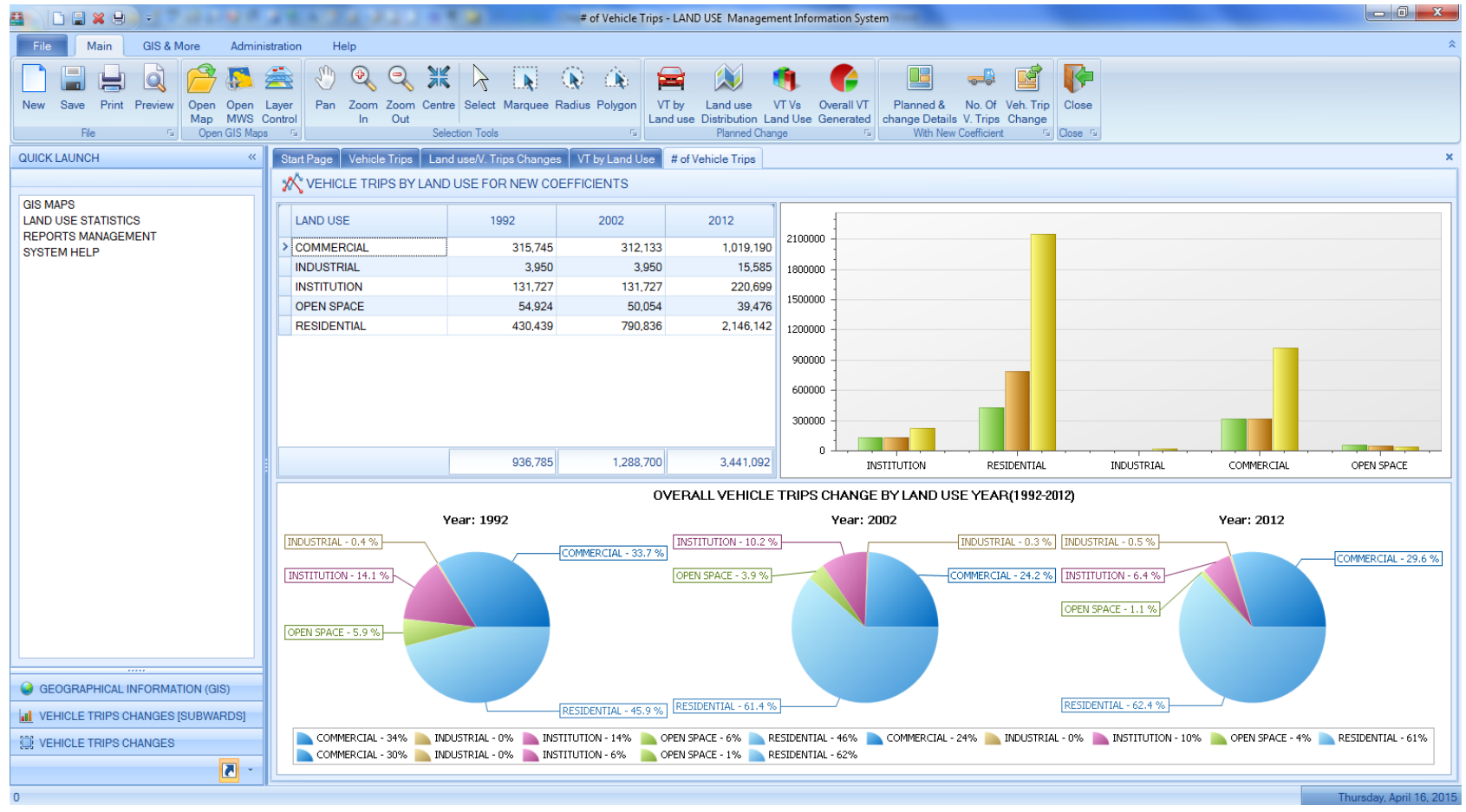

Figure 7. Vehicle trips generated by land uses in years 1992, 2002 and 2012.

\section{Model Provision for Adoptive Options in Minimizing Effects of Change}

The model allows different options from policy makers, planning authorities and 
other stakeholders to be incorporated. Basically, the options presented in this system are featured from land uses data, coefficients used in estimating vehicle trips and household characteristics data obtained in the years 1992, 2002 and 2012. The effects of changing land uses, coefficients and household characteristics are observed by comparing planned data for the year 1992 with the results obtained from different change options for the year 2002 or 2012. There are four change options presented in this system which have based on the scenario that, 1) comparing rate of change for different land use categories, 2) the coefficients remain unchanged but land uses and household characteristics values have changed, 3) household characteristics have remained unchanged but land uses and coefficients have changed, 4) there are some policies implemented therefore vehicle trips have increased or decreased to the defined percentages.

\subsection{Scenario 1: Comparing Rates of Change by Using Manual and New Coefficients}

The option is essentially based on the scenario that, rates of land use and vehicle trip change are different when compared by using manual or planned coefficients and new or calibrated coefficients. As presented in Figure 8 and Figure 9 below, between 1992-2012, the rate of land uses change is about 9 percent and vehicle trips computed by application of manual coefficients is about 39.7 percent; while vehicle trip change computed by new coefficients is about 267.3 percent.

The discrepancies between vehicle trips computed by manual and new coefficients is basically caused by increased commercial areas which have more trip

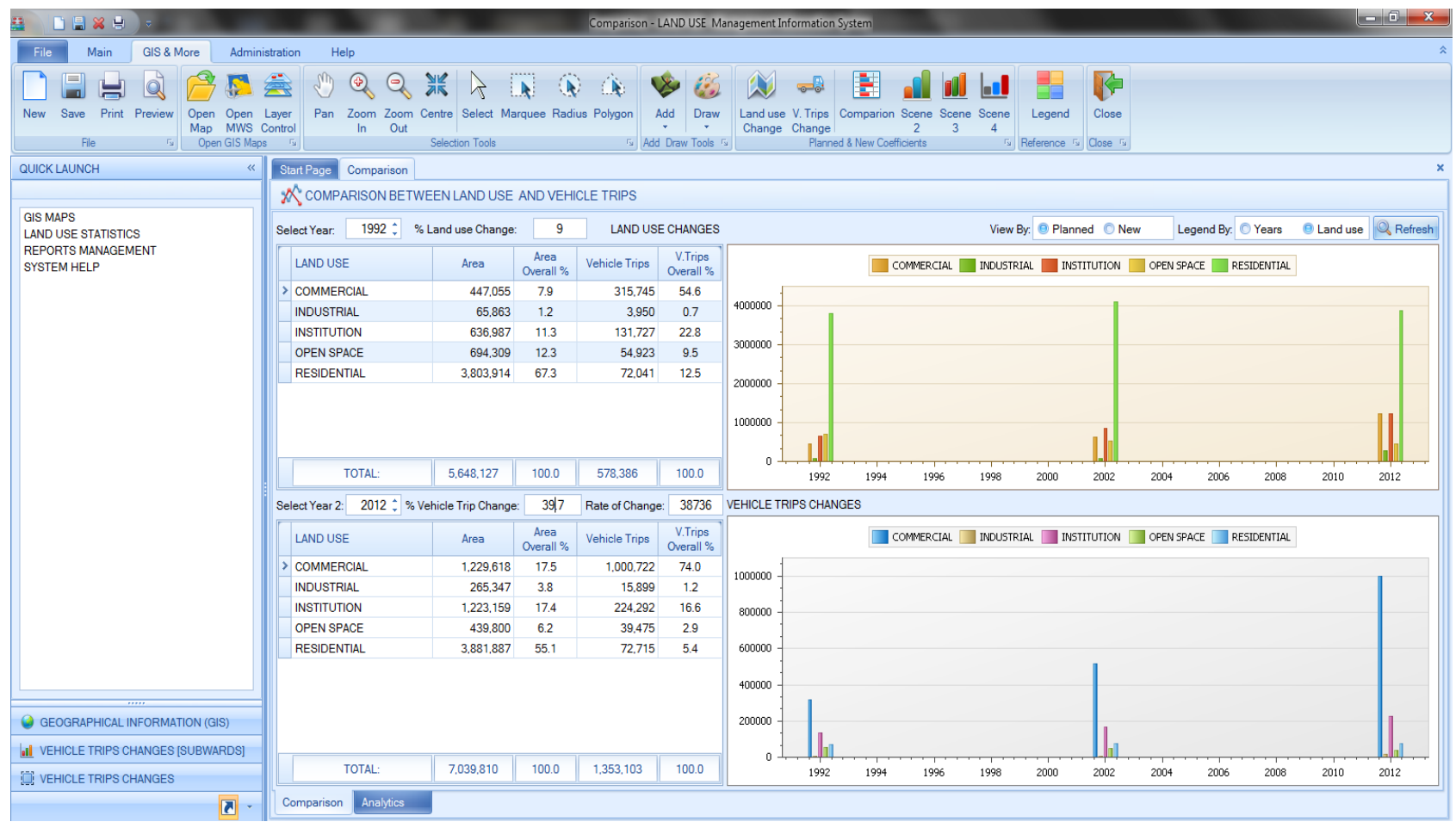

Figure 8. Comparisons between land use and vehicle trip change in years 1992-2002 based on the manual or planned coefficients. 


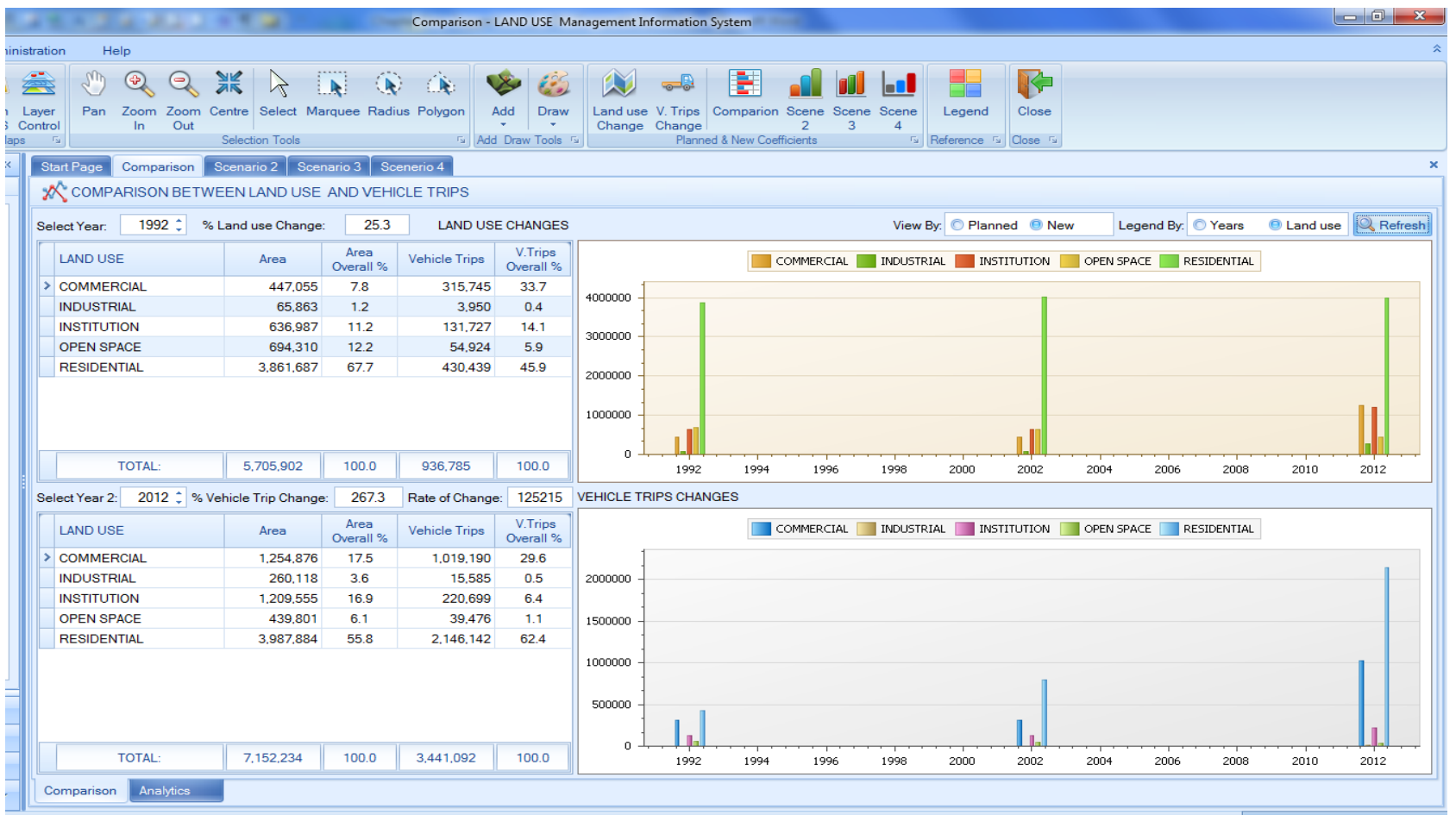

Figure 9. Comparisons between land use and vehicle trip change in years 1992-2012 based on new coefficients.

rates when forecasting vehicle trips basing on manual rates, whereas, both residential and commercial areas have higher trip rates when forecasting trips based on new coefficients.

The observed differences in comparing the changes by using manual and new coefficients portray the effectiveness and deficiencies for both items. Forecasting trips based on manual coefficients will actually underestimate the values of vehicle trips to be generated by the planned areas. Estimating trips by using new rates will incorporate rates of land use change that depict realities in forecasting trips for future development.

\subsection{Scenario 2: Trip Generation under Consideration of Change of Household Characteristics Values and Manual Coefficients}

This option takes into account the change of household characteristics values considered in estimating vehicle trips generated by different land use categories. Household characteristics include household size, vehicle owned by the household, employees, income, number of people in the household. Within the system, the values of each household characteristic are multiplied to the land use data and therefore included as the factor of trip estimation.

As presented in Figure 10 above, vehicle trips estimated by using manual rates are quite lower than trips estimated by considering the values of household characteristics obtained in the study area. This situation reveals effect of household characteristics in travel estimation that need to be critically analysed and effectively incorporated in transport planning. 


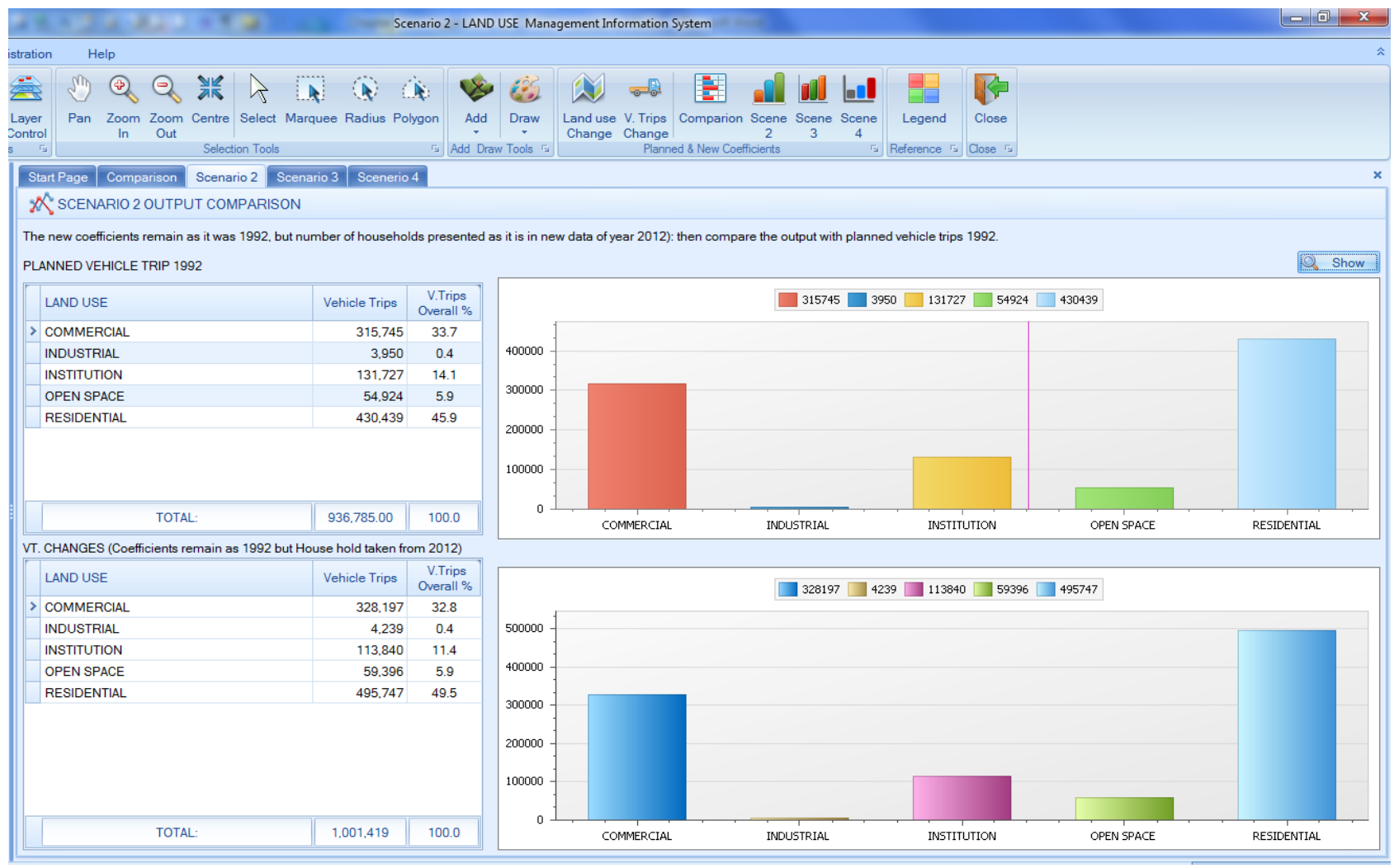

Figure 10. Comparisons between changed household characteristics values and vehicle trips generated by manual coefficients.

\subsection{Scenario 3: Trip Generation under Consideration of Change of Household Characteristics Values and New Coefficients}

This option takes into consideration that changes of household characteristics are incorporated on vehicle trips estimated by using new coefficients. As presented in Figure 11 below, vehicle trips estimated using new coefficients by incorporating the household characteristic values are quite high compared with the previous option that incorporated household characteristic values with manual coefficients. This situation indicates that, estimating and forecasting trips using new coefficients is more effective, however both new coefficient and household characteristic values are required in presenting realistic and effective transport demand forecasting.

\subsection{Scenario 4: Increasing or Decreasing of Trip Generation Percentages}

This option considers that deliberate actions and strategies are implemented in order to either increase or decrease the vehicle trips generated in the planning area. Some of the strategies include implementation of congestion charging systems, transit-oriented development strategies, park and ride systems and others. As presented in Figure 12 below, the system helps to determine the number of vehicle trips that should be generated by defining the percentages of increase or decrease directly into the model. 


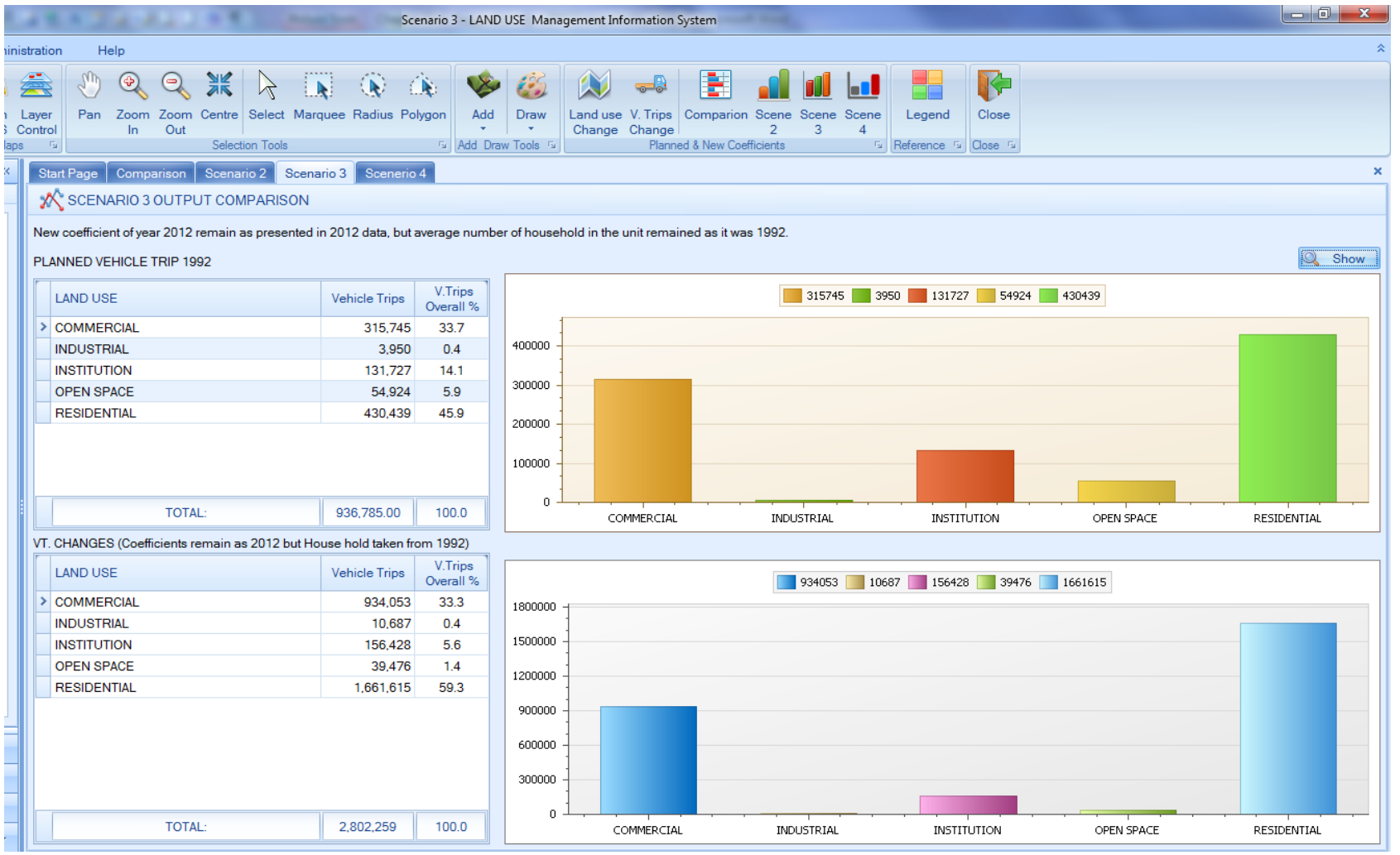

Figure 11. Comparisons between changed household characteristics values and vehicle trips generated by new coefficients.

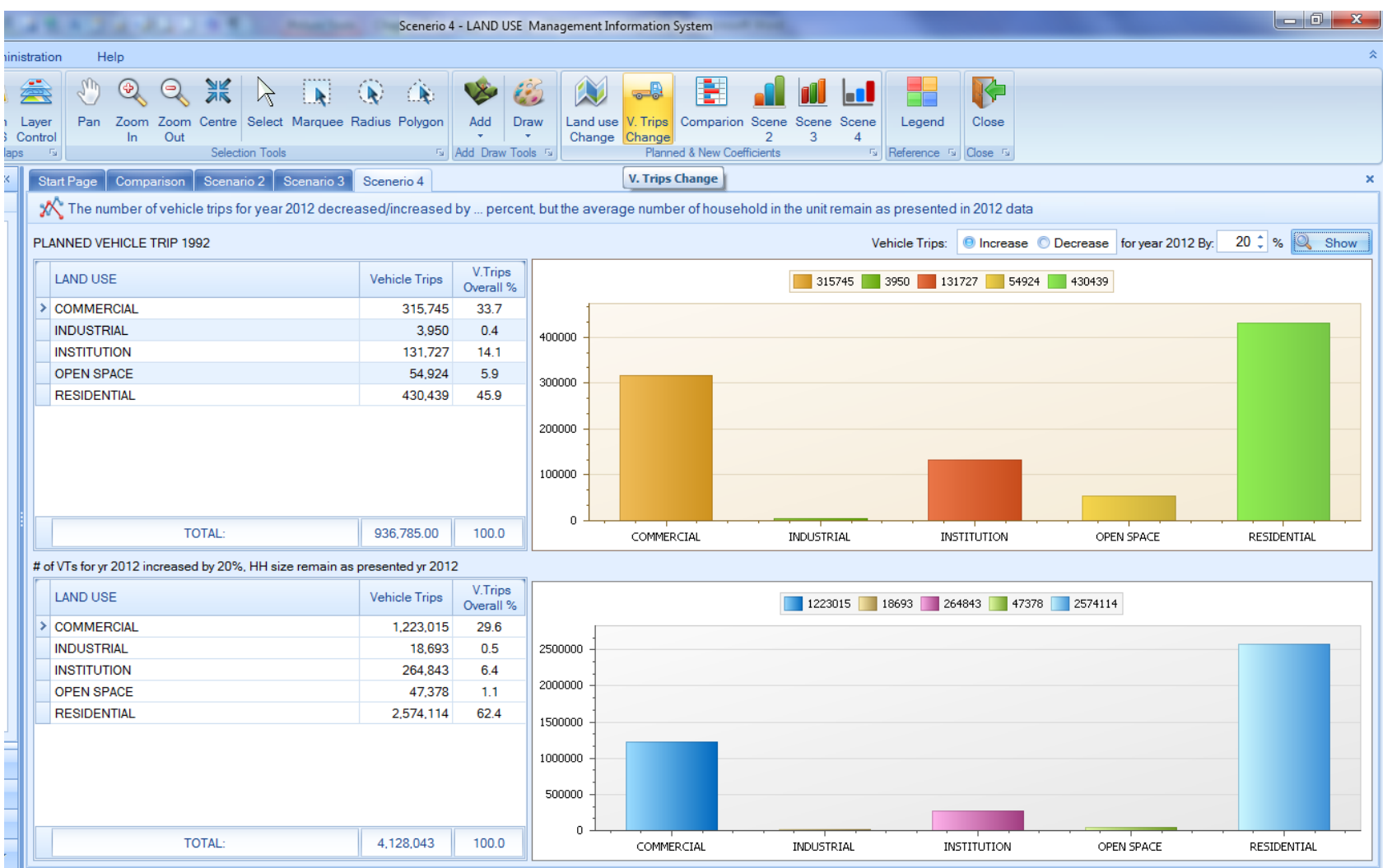

Figure 12. Comparisons between planned vehicle trips and trips generated by increasing or decreasing percentages. 


\section{Conclusion and Recommendations}

\subsection{Conclusion}

Difficulties in detecting, analysing and integrating rates of change in transport planning are experienced in fast developing cities where irregular changes of land uses and buildings evolve over time. Land use changes result in rapid population increase and generation of undetermined vehicle trips that deliberately affect the existing transport network. The great challenge to transport and land use planners encompass the complexity of determining and integrating rates of changes during estimating and forecasting transport demands. This study therefore developed a GIS-based system capable of detecting, analysing and integrating the rates of land use change during transport planning. It is a powerful tool for handling spatial data, attributes data in an integrated environment, and is also extended to include the temporal data that help to determine the spatial and attribute changes within specified time intervals.

The system provides a dynamic and interactive environment that is much more flexible during forecasting transport demands. Urban transport planners not only can manipulate the rates of change in land uses and additional trips rates generated after land use change, but also can change the data views, alter trip generation coefficients, query data and present results easily in different scenarios.

\subsection{Recommendations}

Policies frameworks and guidelines, together with technical and practical consequences limit the effective uses of GIS-based model in cities of developing countries. Basically, these restrictions are categorized into two parts, first are factors that limit system developments and second are those factors that limit system functionality.

\subsubsection{The Model Development}

Development of a GIS-based model is complex since it should be capable of analysing and integrating spatial changes in a spatial temporal manner, and be able to determine different options of any anticipated interventions. The developed model, therefore, should have the following capabilities:

\section{1) Spatial-Temporal Integrations Capabilities}

GIS-based system should be able to determine the spatial differences between land use of the base year and other land uses of subsequent years. It should also perform multi-dependency integrations between attributes of changed land uses and other databases in different formats. Additionally, the system should allow integration of temporal datasets that help to determine the rate of change between land use and transportation during different time scales. On the other hand, the system should detect and monitor changes in order to be able to determine extra trips influenced by changes, together with relevant coefficients of estimating and predicting travel demand. Continuous monitoring of changes 
should be implemented efficiently for the best updating of information that could effectively be applied in updating trip generation rates.

\section{2) Scenario Development Capabilities}

The GIS-based model should have the capability of determining different options proposed to deal with the analysed issues. In most cases, options are deliberate interventions defined in different policies, or mechanisms proposed by researchers. The flexibility of the system applications is measured in these operations, whereby the system allows customizations of different tools or extensions of different modules in order to be applied for different applications.

\subsubsection{System Functionality}

The functionality of the GIS-based model will basically depend on the availability of data, availability of experienced experts and a systematic way of sharing data in the data scarce environment. The study suggestions can be described as follows:

\section{1) The Framework for Storage of Spatial-Temporal Data}

The effective applications of the GIS system depend much on the availability of consistent and suitable data. Spatial data are basically obtained from satellite images, and variations of time horizons should be set for deriving the temporal effects depending on the availability of satellite data. The practical applications of the time scaled data are limited with unavailability of satellite images in suppliers' archives; however, the purchases for the new images are very expensive and unaffordable. This study suggests that the government develops a geospatial information centre that can retrieve the satellite data from different sources or suppliers and stock up at different time scales in order to make them available for different applications. It is unreasonable and unrealistic for the transport planner in Tanzania to request for satellite images from ten years ago from the archives of resellers and producers. The specific country or city should store all necessary satellite images and orthophotos at the time of production in order to make them available for different applications.

\section{2) Availability of GIS Experts in Urban Planning Authorities}

The practical and extensive application of GIS-based model in planning exercises is implicated by the availability of experienced experts in urban planning authorities. Mainly the required experts should not only include planners and engineers with practical knowledge of GIS and remote sensing, but also should be conversant in formulating programming models, developing new systems and customizing the existing systems. Realistically, the effective application of GIS systems in transport planning requires recruitment of enough and authentic experts for the applications of available GIS software together with real experts for developing new systems or customizing the available systems.

\section{3) Development of Sustainable Information Sharing Systems}

The GIS based system should be supported by a systematic way of sharing available data. The effectiveness of the GIS system should not only base on the 
raw data, but also on secondary data available in different government sectors and private institutions. This is because we have data scarcity in different databases; moreover, the access to the available data is very complex. This study therefore is suggesting that the government develop guidelines for information communication and sharing in order to enhance the implementation of the GIS system and its application in urban planning.

\section{Areas for Further Studies}

1) This study has explored the effect of land use change on planned residential areas. Since Dar es Salaam and other developing cities are more affected by proliferation of informal settlements, this is the area for further study.

2) The spatial differences or segregation in urban settings has great impact on land use change and transport demand. This is another area of study.

\section{Conflicts of Interest}

The author declares no conflicts of interest regarding the publication of this paper.

\section{References}

Aronoff, S. (2002). Geographical Information System and Remote Sensing Applications. Enschede: International Institute for Aerospace Survey and Earth Science (ITC).

Iacono, M., Levinson, D., \& El-Geneidy, A. (2008). Models of Transportation and Land Use Change: A Guide to a Territory. Journal of Planning Literature, 22, 323-340. https://doi.org/10.1177/0885412207314010

Kenneth, E., \& Lynch, M. (1995). Remote Sensing and Geographic Information Systems, an Integrated Technology: Context, Concepts and Definitions. Austin, TX: The University of Texas Press.

Kwan, M. (2000). Interactive Geo-Visualization of Activity Travel Patterns Using Three Dimensional GIS: A Methodological Exploration with a Large Data Set. Columbus, $\mathrm{OH}$ : The Ohio State University, USA.

Kwan, M., \& Lee, J. (2003). Geo-Visualization of Human Activity Patterns Using 3D GIS: A Time-Geographic Approach. Oxford: Oxford University Press.

Langran, G. (1992). Time in Geographic Information Systems (pp. 334-347). London: Taylor \& Francis.

Michael, G. (2006). Coordinated Transportation and Land Use Planning in the Developing World, The Case of Mexico City.

Miller, J., \& Wu, Y. (2010). GIS Software for Measuring Space-Time Accessibility in Accessibility in Transportation Planning and Analysis: Digitally Integrated Geographical Information Technology (DIGIT) Laboratories. Salt Lake City, UT: University of Utah.

Murai, S. (1998). Geographical Information System Fundamentals. Tokyo: National Press for Association of Surveyors.

Shaw, P. (2006). Development of an Integrated GIS-Based Land Use and Transport Model for Studying Land Use Relocation, Shanghai, China.

Shaw, P., \& Xin, X. (2003). Integrated Land Use and Transportation Integration: A Temporal GIS Exploratory Data Analysis Approach. Journal of Transport Geography, 11, 
103-115. https://doi.org/10.1016/S0966-6923(02)00070-4

Sun, X., Wilmot, G., \& Kasturi, T. (2000). Household Travel, Household Characteristics, and Land Use, an Empirical Study from the 1994 Portland Activity Based Travel Survey. Baton Rouge, LA: Louisiana State University.

Waddell, P., Outwater, M., Bhat, C., \& Blain, L. (2003). Design of an Integrated Land Use and Activity-Based Travel Model System for a Puget Sound Region. Transportation Research Records, 1805, 108-118. https://doi.org/10.3141/1805-13

Wagner, M. (1998). Model of Urban Land Use, Transport and Environment. In L. Lundqvist, L. G. Mattsson, \& T. J. Kim (Eds.), Network Infrastructure and the Urban Environment. Advances in Spatial Science (The Regional Science Series) (pp. 245-267). Berlin, Heidelberg: Springer. https://doi.org/10.1007/978-3-642-72242-4_14

Wei, Z., \& Zhou, F. (2006). Modelling the Spatial-Temporal Patterns of Urban Fringe, a Case Study on Hongshan District of Wuhan City. Wuhan: School of Urban Design, Wuhan University, China.

Worboys, F. (1998). Spatial and Temporal Reasoning in Geographic Information Systems (pp. 25-39). New York: Oxford University Press.

Yang, S. (2007). Analysis of Spatial-Temporal Features in Urban Land Use Growth Based on Remote Sensing and GIS in Wuxi City.

Yuan, M. (1999). Use of a Three-Domain Representation to Enhance GIS Support for Complex Spatiotemporal Queries. Transactions in GIS, 3, 137-159.

https://doi.org/10.1111/1467-9671.00012 